\title{
Correlation of Fractional Flow Reserve with non- invasive tests for the detection of ischaemia due to intermediate coronary artery stenosis
}

\author{
Timothy A Fairbairn*, Adam Mather, John Greenwood, Sven Plein \\ From 2011 SCMR/Euro CMR Joint Scientific Sessions \\ Nice, France. 3-6 February 2011
}

\section{Objectives}

To compare ischaemia assessment by Fractional flow reserve (FFR) with non-invasive testing in patients with intermediate coronary artery stenosis.

\section{Background}

FFR was initially validated against SPECT, Dobutamine Stress Echo and Exercise Testing [1]. It is now frequently used to determine the management of intermediate coronary artery stenosis. A cut-off value of 0.75 is used in clinical practice to guide revascularisation supported by long-term outcome data [2], but a 'grey zone' of $0.75-0.8$ with uncertain clinical significance exists [3]. Advances in non-invasive imaging tests (gated SPECT and CMR) warrant a re-evaluation of FFR at intermediate stenosis severity against non-invasive imaging.

\section{Methods}

Patients due for investigation of presumed cardiac chest pain were recruited and underwent SPECT (Discovery, GE Healthcare), perfusion-CMR (1.5T, Intera, Phillips) and coronary angiography. Any vessel that was angiographically determined as intermediate severity $(40-70 \%)$ was assessed by QCA and pressure wire-derived FFR (RADI medical systems, Uppsala, Sweden).

\section{Results}

In 23 study patients (age $57 \pm 8,78 \%$ male), 33 FFR measurements were performed (LAD 64\%, Cx 18\%, RCA $12 \%$, LMS $6 \%)$. FFR was classified negative $(>0.80)$ in $\mathrm{n}=20$. Perfusion-CMR detected ischaemia in 3 vessels

University of Leeds. Leeds, UK

Full list of author information is available at the end of the article
( 2 with positive FFR and one with 'grey' FFR). SPECT also detected ischaemia in 3 vessels ( 2 negative FFR and one positive FFR), (Table 1). Coronary stenosis by QCA and FFR correlated poorly $(\mathrm{r}=-0.35, \mathrm{p}=0.054)$. Chisquared analysis of FFR severity found no significant association between FFR positivity and perfusion-CMR $(\mathrm{p}=0.078)$ or SPECT $(\mathrm{p}=0.34)$.

\section{Conclusion}

Non-invasive imaging does not correlate well with FFR measurements in intermediate coronary lesions. Perfusion-CMR whilst not significantly discriminating between the groups had no false negatives and may thus be the more useful additional test to determine the significance of 'grey' lesions on FFR.

Table 1 Cross tabulation of Fractional Flow Research grading (negative $\geq 0.8$, grey $0.75-0.79$ and positive $<0.75$ ) and the qualitative result of (A) Perfusion cardiac magnetic resonance (CMR) and (B) SPECT

\begin{tabular}{lllll}
\hline A & & CMR & Total \\
& & Non ischaemic & Ischaemic & \\
\hline FFR & Negative & 20 & 0 & 20 \\
& Grey & 7 & 2 & 9 \\
& Positive & 3 & 1 & 4 \\
Total & & 30 & 3 & 33 \\
\hline B & & SPECT & & \\
& & Non ischaemic & Ischaemic & Total \\
\hline FFR & Negative & 18 & 2 & 20 \\
& Grey & 9 & 0 & 9 \\
& Positive & 3 & 1 & 4 \\
Total & & 30 & 3 & 33 \\
\hline
\end{tabular}




\section{References}

1. Pijls NH: N Engl J Med 1996, 334(26):1703-8.

2. Tonino PA: N Engl J Med 2009, 360(3):213-24.

3. De Bruyne B: Heart 2008, 94(7):949-59.

doi:10.1186/1532-429X-13-S1-P85

Cite this article as: Fairbairn et al: Correlation of Fractional Flow Reserve with non-invasive tests for the detection of ischaemia due to

intermediate coronary artery stenosis. Journal of Cardiovascular Magnetic

Resonance 2011 13(Suppl 1):P85.

Submit your next manuscript to BioMed Central and take full advantage of:

- Convenient online submission

- Thorough peer review

- No space constraints or color figure charges

- Immediate publication on acceptance

- Inclusion in PubMed, CAS, Scopus and Google Scholar

- Research which is freely available for redistribution

Submit your manuscript at www.biomedcentral.com/submit
() Biomed Central 